\title{
Uniaxial Orientation of a Rod-Like Helical Poly(phenylacetylene) in an Electric Field
}

Kento Okoshi, ${ }^{* \dagger}{ }^{\text {Takashi Kajitani, }}{ }^{\dagger}$ Kanji Nagai ${ }^{\ddagger}$ and Eiji Yashima ${ }^{*} \dagger, \ddagger$

${ }^{\dagger}$ Yashima Super-structured Helix Project, Exploratory Research for Advanced Technology (ERATO), Japan Science and Technology Agency (JST), 101 Creation Core Nagoya, 2266-22 Anagahora, Shimoshidami, Moriyama-ku, Nagoya 463-0003, Japan, and ${ }^{\ddagger}$ Department of Molecular Design and Engineering, Graduate School of Engineering, Nagoya University, Chikusa-ku, Nagoya 464-8603, Japan

Materials. Anhydrous benzene (water content $<50$ ppm) was purchased from Wako (Osaka, Japan) and used for the preparation of the oriented films in an electric field. Stereoregular (cis-transoid) poly-L-1 was prepared according to a previously reported method using a rhodium catalyst in $\mathrm{THF}^{1}$

Instruments. The polarized IR spectra were recorded using a JASCO FT/IR-680Plus spectrometer (JASCO, Tokyo, Japan) connected to an Irtron IRT-30 microscope unit. The polarizing optical microscopic observations were carried out using an E600POL polarizing optical microscope (Nikon, Tokyo, Japan) equipped with a DS-5M CCD camera (Nikon) connected to a DS-L1 control unit (Nikon). The WAXD measurements were performed using a Rigaku RINT RAPID-R X-ray diffractometer (Rigaku, Tokyo, Japan) with a rotating-anode generator and graphite monochromated $\mathrm{CuK} \alpha$ radiation $(0.15418 \mathrm{~nm})$ focused through a $0.3 \mathrm{~mm}$ pinhole collimator, which was supplied at a 45 $\mathrm{kV}$ voltage and a $60 \mathrm{~mA}$ current, equipped with a flat imaging plate having a specimen-to-plate distance of $120.0 \mathrm{~mm}$. The X-ray photographs were taken at ambient temperature $\left(20-25{ }^{\circ} \mathrm{C}\right)$ from the through-view position with a beam perpendicular to the film surface. The high electric field was generated using a high voltage V7032A DC power supply (Kawaguchi Electric Works, Tokyo, Japan).

Oriented Film Preparation in the Electric Field. The oriented poly-L-1 films for the polarized IR and 
X-ray measurements were prepared by gradual solvent evaporation of a concentrated LC benzene solution (5.0 and $10.4 \mathrm{mg} / \mathrm{mL}$ ) of poly-L-1 in a benzene vapor atmosphere on $\mathrm{CaF}_{2}$ and PTFE substrates in an electric field of $6000 \mathrm{~V} / \mathrm{cm}$ in a PTFE cell (Figure S1). After drying in air, the oriented poly-L-1 films for the X-ray measurements were floated off the PTFE substrates onto a water surface, carefully collected, and then dried.

Molecular Modeling and Calculations of Helical Structure of Poly-L-1. We explored the helical conformation of poly-L-1 using Miyazawa's equation. ${ }^{2}$ According to Miyazawa, the helical parameters (unit height $(h)$ and number of repeating units $(n)$ per one helical turn) of infinite (periodic) polymer chains can be described by internal coordinates, such as the bond lengths $\left(\mathrm{C}-\mathrm{C}_{1}\left(r_{1}\right)\right.$ and $\left.\mathrm{C}_{1}=\mathrm{C}_{2}\left(r_{2}\right)\right)$, the bond angles $\left(\mathrm{C}-\mathrm{C}_{1}(\mathrm{H})=\mathrm{C}_{2}\left(\phi_{1}\right)\right.$ and $\left.\mathrm{C}_{1}=\mathrm{C}_{2}(\mathrm{Ph})-\mathrm{C}\left(\phi_{2}\right)\right)$, and the internal rotation angles $\left(\mathrm{C}-\mathrm{C}_{1}=\mathrm{C}_{2}-\mathrm{C}\right.$ $\left(\tau_{1}\right)$ and $\left.\mathrm{C}=\mathrm{C}-\mathrm{C}_{1}=\mathrm{C}_{2}\left(\tau_{2}\right)\right)$. The bond lengths were set to $r_{1}=1.466 \AA$ and $r_{2}=1.374 \AA$ on the basis of the calculated structure of a cis-transoidal phenylacetylene heptamer using the density functional theory (DFT) at the B3LYP level ${ }^{3}$ and the 6-31G basis set in the Gaussian 03 program (Gaussian, Inc., Pittsburgh, PA). ${ }^{4}$ The bond lengths of the central monomer unit of the optimized heptamer were employed as the bond lengths in order to avoid any influence by the end groups. The internal rotation angle, $\tau_{l}$, was fixed to $0^{\circ}$ (cis). The other internal coordinate combinations were calculated by Miyazawa's equation so as to satisfy the helical parameters $(h ; 2.12 \AA$ and $n ; 2.2)$ obtained by the X-ray analysis and AFM observations. ${ }^{5}$ Here, $\phi_{1}$ was set to $110-140^{\circ}$ at $0.5^{\circ}$ intervals, then $\phi_{2}$ and $\tau_{2}$ were calculated accordingly.

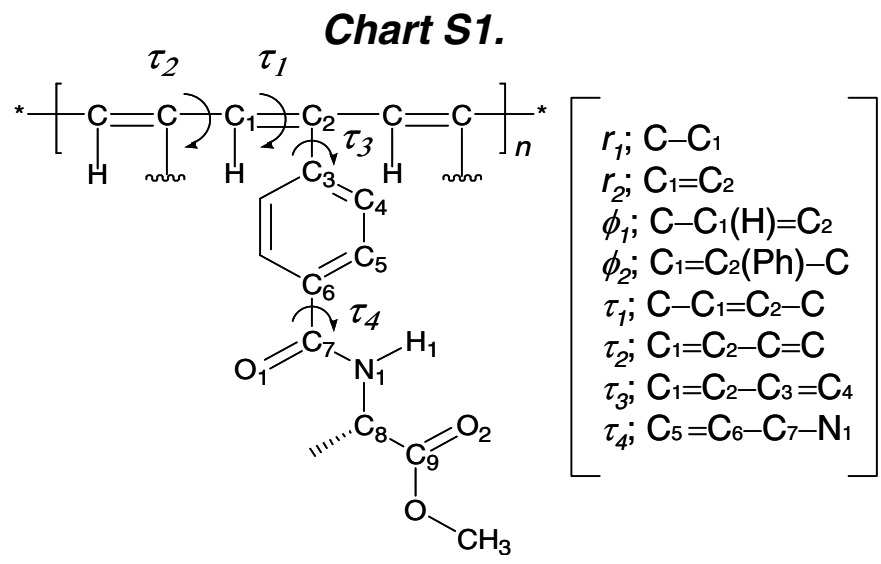


The atomic connectivities and dihedral angles of poly-L-1 are depicted in Chart S1. The MM calculations were conducted using the Compass force field ${ }^{6}$ as contained in the MS Modeling software (version 4.1, Accelrys, Inc., San Diego, CA) operated using a PC running under Windows ${ }^{\circledR}$ XP.

In order to search for a suitable starting side chain conformation for the $11 / 5$ helical structure of poly-L-1, ${ }^{5}$ we constructed 50 -mer of poly-L-1 having the possible combinations of the side chain dihedral angles of $\mathrm{C}_{1}=\mathrm{C}_{2}-\mathrm{C}_{3}=\mathrm{C}_{4}\left(\tau_{3}\right)=0^{\circ}, 45^{\circ}, 90^{\circ}$, and $135^{\circ}$ and $\mathrm{C}_{5}=\mathrm{C}_{6}-\mathrm{C}_{7}-\mathrm{N}_{1}\left(\tau_{4}\right)=0^{\circ}, 45^{\circ}, 90^{\circ}$, $135^{\circ}, 180^{\circ}, 225^{\circ}, 270^{\circ}$, and $315^{\circ}$ so as to maintain the intramolecular hydrogen bonding networks between the amide residues of the neighboring pendants ( $n$ and $n+2)$ using the Polymer Builder module in MS Modeling software. After each initial structure was energy minimized, the central 30 monomer units of the optimized structures were employed to calculate the total potential energies in order to avoid any influence by the end groups. The geometrical parameters of the monomer unit of the optimized polymer models with the lowest total potential energy were $\tau_{3}=-70.2^{\circ}$ and $\tau_{4}=115.0^{\circ}$; these values were used as a starting side chain conformation for further structural optimizations of the polymer main chain.

The polymer model (70-mer) of poly-L-1 were then constructed based on the internal coordinate combinations calculated by Miyazawa's equation with a suitable side chain starting conformation. The long decyl group was replaced by the methyl group for clarity. The geometrical parameters for the poly-L-1 backbone were fixed during the following force field optimization. The dielectric constant was set to 1.0. The geometry optimizations were carried out without any cutoff by the smart minimizer in three steps. First, the starting conformation was subject to the steepest decent optimization in order to eliminate the worse steric conflicts. Second, subsequent optimization until the convergence using the conjugate gradient algorithm was performed. Finally, the finest optimization using the Newton method was carried out with the $0.1 \mathrm{kcal} / \mathrm{mol} / \mathrm{A}$ convergence criterion. The internal coordinates combinations with the lowest energy was as follows: the bond lengths $\left(r_{1}: 1.466 \AA\right.$ and $r_{2}: 1.374 \AA$ ), the bond angles 
$\left(\phi_{1}: 126.0^{\circ}\right.$ and $\left.\phi_{2}: 120.3^{\circ}\right)$, and the internal rotation angles $\left(\tau_{1}: 0^{\circ}\right.$ and $\left.\tau_{2}: 149.8^{\circ}\right)$. The final helical poly-L-1 model is shown in Figures 3a-3c with the two sets of hydrogen-bonded helical arrays ( $n$ and $n$ +2 ) of the pendants shown in different colors for clarity.

Calculation of the Relative Polarized IR Absorption. We calculated the relative polarized IR absorptions for selected functional groups using the central part of the optimized poly-L-1 model (50-mer), where the main-chain helical axis was placed on the z-axis in the Cartesian coordinate. The calculation was conducted considering the fact that the vibrational transition moment vectors of the $\mathrm{C}_{7}=\mathrm{O}_{1}$ and $\mathrm{C}_{9}=\mathrm{O}_{2}$ bonds in the amide and ester groups are inclined at $20^{\circ}$ and $19^{\circ}$ from the corresponding bond directions toward the $\mathrm{C}_{7}-\mathrm{N}_{1}$ and $\mathrm{C}_{9}-\mathrm{C}_{8}$ bond directions, respectively, and that the vibrational transition moment vectors of the $\mathrm{N}-\mathrm{H}$ bond is nearly identical to the direction of the $\mathrm{N}-\mathrm{H}$ bond. $^{7}$

Since the polarized IR absorption is proportional to the squared scalar product of the projected electric vector of the incident light on the vibrational transition moment, the relative IR absorption of a particular functional group in the model can be expressed in terms of the polarization angle $\theta$ by

$$
\begin{aligned}
& A(\theta) \propto \sum_{i=1}^{n}\left(\left[\left(\begin{array}{ccc}
\cos \theta & 0 & \sin \theta \\
0 & 1 & 0 \\
-\sin \theta & 0 & \cos \theta
\end{array}\right)\left(\begin{array}{l}
0 \\
0 \\
1
\end{array}\right)\right]^{T}\left(\begin{array}{l}
v_{x i} \\
v_{y i} \\
v_{z i}
\end{array}\right)\right)^{2} \\
& v_{i}=\left(\begin{array}{l}
v_{x i} \\
v_{y i} \\
v_{z i}
\end{array}\right)
\end{aligned}
$$

where $\mathrm{v}_{i}$ denotes the unit vibrational transition moment vector of a particular functional group in the $i$ th monomer unit. The calculated values were then plotted versus the polarization angle $\theta$ with respect to 
the direction of the main-chain helical axis (Figure 3d).

\section{References}

(1) Okoshi, K.; Sakajiri, K.; Kumaki, J.; Yashima, E. Macromolecules 2005, 38, 4061-4064.

(2) Miyazawa, T. J. Polym. Sci. 1961, 55, 215-231.

(3) Nagai, K.; Sakajiri, K.; Maeda, K.; Okoshi, K.; Sato, T.; Yashima, E. Macromolecules 2006, 39, 5371-5380.

(4) Frisch, M. J.; Trucks, G. W.; Schlegel, H. B.; Scuseria, G. E.; Robb, M. A.; Cheeseman, J. R.; Montgomery, J. A., Jr.; Vreven, T.; Kudin, K. N.; Burant, J. C.; Millan, J. M.; Iyengar, S. S.; Tomasi, J.; Barone, V.; Mennucci, B.; Cossi, M.; Scalmani, G.; Rega, N.; Petersson, G. A.; Nakatsuji, H.; Hada, M.; Ehara, M.; Toyota, K.; Fukuda, R.; Hasegawa, J.; Ishida, M.; Nakajima, T.; Honda, Y.; Kitao, O.; Nakai, H.; Klene, M.; Li, X.; Knox, J. E.; Hratchian, H. P.; Cross, J. B.; Adamo, C.; Jaramillo, J.; Gomperts, R.; Stratmann, R. E.; Yazyev, O.; Austin, A. J.; Cammi, R.; Pomelli, C.; Ochterski, J. W.; Ayala, P. Y.; Morokuma, K.; Voth, G. A.; Salvador, P.; Dannenberg, J. J.; Zakrzewski, V. G.; Dapprich, S.; Daniels, A. D.; Strain, M. C.; Farkas, O.; Malick, D. K.; Rabuck, A. D.; Raghavachari, K.; Foresman, J. B.; Ortiz, J. V.; Cui, Q.; Baboul, A. G.; Clifford, S.; Cioslowski, J.; Stefanov, B. B.; Liu, G.; Liashenko, A.; Piskorz, P.; Komaromi, I.; Martin, R. L.; Fox, D. J.; Keith, T.; Al-Laham, M. A.; Peng, C. Y.; Nanayakkara, A.; Challacombe, M.; Gill, P. M. W.; Johnson, B.; Chen, W.; Wong, M. W.; Gonzalez, C.; Pople, J. A.; Gaussian 03; Gaussian, Inc.: Pittsburgh, PA, 2003.

(5) Sakurai, S.-i.; Okoshi, K.; Kumaki, J.; Yashima, E. Angew. Chem., Int. Ed. 2006, 45, 1245-1248.

(6) Sun, H. J. Phys. Chem. B 1998, 102, 7338-7364.

(7) (a) Bradbury, E. M.; Elliott, A.; Fraser, R. D. B. Trans. Faraday. Soc. 1960, 56, 1117-1124. (b) 
Fraser, R. D. B. J. Chem. Phys. 1958, 28, 1113-1115. (c) Fraser, R. D. B. J. Chem. Phys. 1953, 21, 1511-1515. 


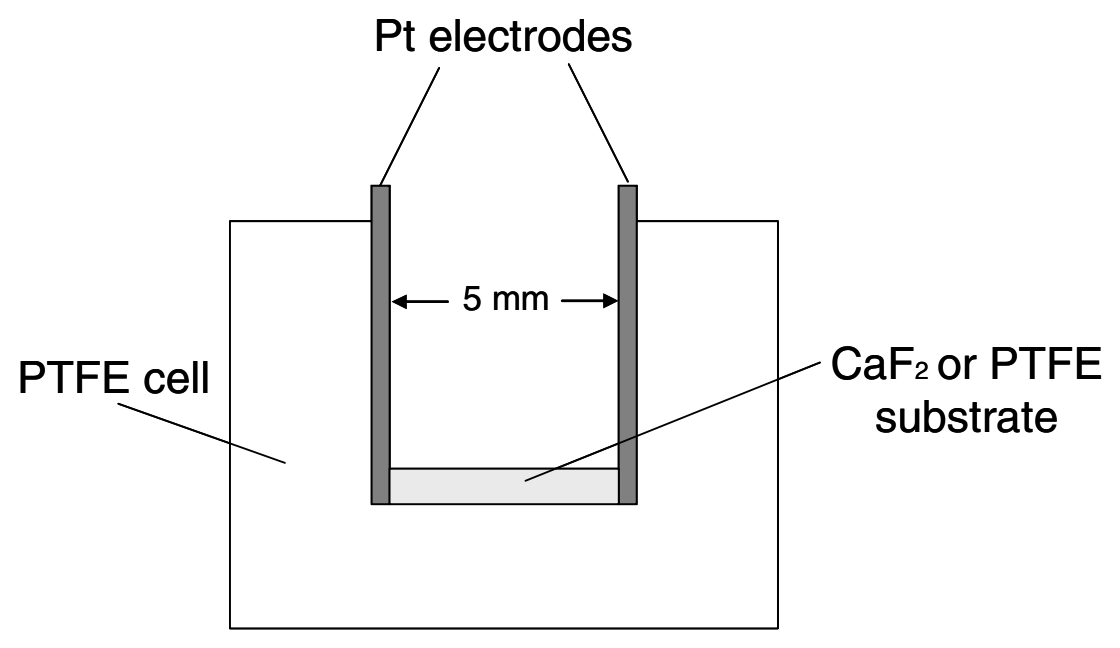

Figure S1. Schematic depiction of the PTFE cell and the platinum electrodes used for preparation of the oriented poly-L-1 film.

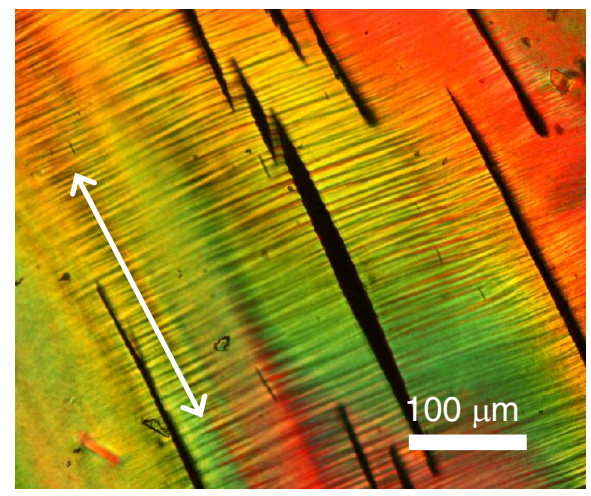

Figure S2. Polarized optical micrograph of an oriented poly-L-1 film. The white arrow indicates the direction of the applied electric field. The banded texture appeared perpendicular to the electric field direction. 